\title{
LAGRANGIAN DROGUE-BASED DRIFTER FOR MONITORING SUSPENDED SEDIMENT TRANSPORT IN INTERTIDAL ENVIRONMENTS
}

\author{
Takahiro Nishi ${ }^{1}$, Charles Lemckert ${ }^{2}$, Kentaro Hayashi ${ }^{3}$ and Fumihiko Yamada ${ }^{4}$
}

\begin{abstract}
The in-situ Lagrangian-Acoustic Drogue (LAD) presented by Schacht and Lemckert (2007) for monitoring the temporal and spatial distributions of both the current and the suspended sediment concentration within the estuary environments has been modified to operate in the shallow water intertidal regions. The new drogue, called the LAD for Inter-Tidal environments (LAD-IT), is equipped with a Global Positioning System (GPS), a small Acoustic Doppler Current Profiler (ADCP) and nephelometer. The small ADCP, which did not have a bottom tracking facility, was used to maximize the range of depths the LAD-IT could operate over. The accuracy of a vertical current profile measured using the LAD-IT was examined through the laboratory experiments conducted at an outdoor stream pool in Kumamoto, Japan, with uni-directional flow conditions, and through the field experiments conducted within an intertidal zone of Ariake Sound in Kumamot, Japan, with multi-directional flow conditions. Under uni- directional flow conditions the current profile was measured within $7 \%$ accuracy by summing the surface current velocity calculated using GPS tracking and the relative current profile measured using ADCP. Under multi-directional flow conditions, such as those of tide and wind-induced wave fields, the current profile agreed within $5 \%$ accuracy. This was partly because both Eulerian and Lagrangian mass transport velocities under these conditions were on the order of $1 \mathrm{~cm} / \mathrm{s}$, and thus the error value was very small. The temporal and spatial distributions of both the current velocity and the suspended sediment concentration were also measured using the LAD-IT on the Brisbane River, Australia under uni-directional flow conditions. The field observation results support the conventional concept of the suspended sediment as a vertical balance between downward suspended sediment settling and upward turbulent diffusion fluxes. The results indicate the LAD-IT is adequate for estimating the sediment settling velocity in the field.
\end{abstract}

Keywords: Lagrangian measurements, water tracking ability, settling velocity

\section{INTRODUCTION}

The sediment settling velocity and the resuspended rate are the important parameters for the predictions of the suspended sediment dynamics and the geomorphological changes within estuaries and intertidal mudflat. These parameters are also required for understanding the transport mechanisms and the fate of suspended sediment, salinity, temperature, dissolved organic substances and biological organisms (Voulgaris and Meyers, 2004; Winterwerp, 2002). These parameters depend on a number of interacting physical processes such as tides, wind waves, river discharge and infrequent storm events (e.g. Naudin et al., 1997; Geyer et al., 2004; Yamada et al., 2008), which are complex a cannot be produced precisely in laboratory experiments. Therefore, the settling velocity and the resuspension rate should be determined in-situ (Sternberg et al., 1999).

The Owen Tube has been used extensively to determine the settling velocities in the field (e.g. Dyer et al., 1996), but the unreliable velocities are obtained due to the breaking of the large fragile flocs during sampling (Dyer et al., 1996; Van Leussen, 1999). To overcome this limitation, the nonintrusive settling velocity measuring instruments have been developed such as those based on the optical devices using Optical Backscatter Sensors (OBS) and transmissometers, laser diffraction instruments such as the LISST-100, Sequoia Scientific, Inc. (Gartner et al., 2001; Mikkelsen and Pejrup, 2000), and acoustic backscatterance devices such as the Acoustic Doppler Current Profiler (ADCP) (Holdaway et al., 1999; Hill et al., 2003). Although these instruments are adequate for nonintrusive measurements, they are often used in an Eulerian set-up that cannot be used to explain the sediment transport mechanisms such as advection-diffusion, local sediment pick-up, and settling (Mikkelsen et al., 2006). Consequently, Lagrangian frameworks for measuring the sediment transport dynamics within estuaries and intertidal environments are required.

Conventionally, Lagrangian frameworks using a drogue-based drifter have been used for the offshore surface current measurements (Righi and Strub, 2001; Niller et al., 1995). Recently, a

\footnotetext{
${ }^{1}$ Engineering Division, Alpha Hydraulic Engineering Consultants Co., Ltd., 516-336 9-14 Hassamu Nishi-ku, Sapporo, Hokkaido, 063-0829, Japan

${ }^{2}$ Griffith School of Engineering, Griffith University, Gold Coast campus, QLD 4222, Australia

${ }^{3}$ Engineering Division, Alpha Hydraulic Engineering Consultants Co., Ltd., 516-336 9-14 Hassamu Nishi-ku, Sapporo, Hokkaido, 063-0829, Japan

${ }^{4}$ Graduate School of Science and Technology, Kumamoto University, 2-39-1, Kurokami, Kumamoto, 860-8555, Japan
} 
number of drifters equipped with a Global Positioning System (GPS) have been used for measuring the spatial circulation patterns in the near-shore (e.g. Johnson and Pattiaratchi, 2004; Schmidt et al., 2003, 2005). Lagrangian drifters have also been used for understanding the larval dispersal and the metacoummunity dynamics in marine ecological studies (Seigel et al., 2003; Guichard, et al., 2004). To the author's best knowledge, little work is currently available on Lagrangian frameworks for monitoring the temporal and spatial distributions of both current velocity and suspended sediment concentration within itnertidal environments.

Schacht and Lemckert (2007) designed a Lagrangian-Acoustic Drogue (LAD) for monitoring three-dimensional suspended-load fluxes in estuaries. This instrument was equipped with the Differential Global Positioning System (DGPS), GeoXM, Trimble, the ADCP, RD Instruments, with a bottom tracking ability and the Conductivity-Temperature-Depth (CTD), CTDP 300, Greenspan, sensor to detect suspended sediment dynamics with both temporal and spatial distributions. The water tracking ability of the drifter requires clarification before using it in the field, as drogue-based drifters are affected by a number of external forces such as tidal current, wind, waves, and water column temperature, density and salinity stratification (Niller et al., 1995). Schacht and Lemckert (2007) concluded that the LAD follows a Lagrangian water parcel to a depth of $4.5 \mathrm{~m}$ within estuary environments. The aim of this study is modify the LAD so it could be adequate in very shallow water regions. The improved LAD is referred here as the LAD for Inter-Tidal environments (LAD-IT). The accuracy of the LAD-IT in measuring the current profile is examined in both the laboratory (unidirection flow) and the field (multi-direction flow) experiments. The temporal and spatial distributions of both current velocity and suspended sediment concentration are also measured by using the LAD-IT under uni-directional flow conditions.

\section{IMPROVEMENT OF LAGRANGIAN-ACOUSTIC DROGUE}

The drogue's dimensions, the vanes and bouy of the original LAD have been shown to be adequate for estuary environment by Schacht and Lemckert (2007), and thus are maintained in the LAD-IT. The LAD-IT was equipped with three instruments for monitoring the temporal and spatial changed of suspended sediment dynamics with Lagrangian framework (Fig.1). The GPS ,GPSMAP 60CSx; GARMIN, the ADCP without bottom tracking ability ,Aquadopp Current Profiler, Nortek; referred here as the Aquadopp-ADCP and the nephelometers, ANALITE 190; McVAN Instrument, were employed. The instruments on the LAD-IT are easily exchanged to fit the purpose and conditions of the field experiments. The GPS was set up in a waterproof container on the top of the LAD-IT to acquire the drogue position autonomously during survey periods for determining the path and estimating the surface velocity. The velocity magnitude and direction along the water column is measured by Aquadopp-ADCP facing downwards on the LAD-IT. This ADCP was chosen, as it was smaller in size than that used on the original LAD. Five nephelometers were hung at equal intervals of $50 \mathrm{~cm}$ below the drogue for monitoring turbidity vertical distributions. The accuracy of the LAD-IT in measuring the current profiler is examined in both laboratory experiments conducted at an outdoor stream pool in Kumamoto, Japan, under uni-directional flow conditions, and in field experiment conducted within an intertidal zone of Ariake sound in Kumamoto, Japan, under multi-directional flow conditions. After confirming the accuracy measuring the current profiler, the temporal and spatial distributions of both current velocity and suspended sediment concentration measured for Brisbane River in Australia, using the LAD-IT are examined in detail.

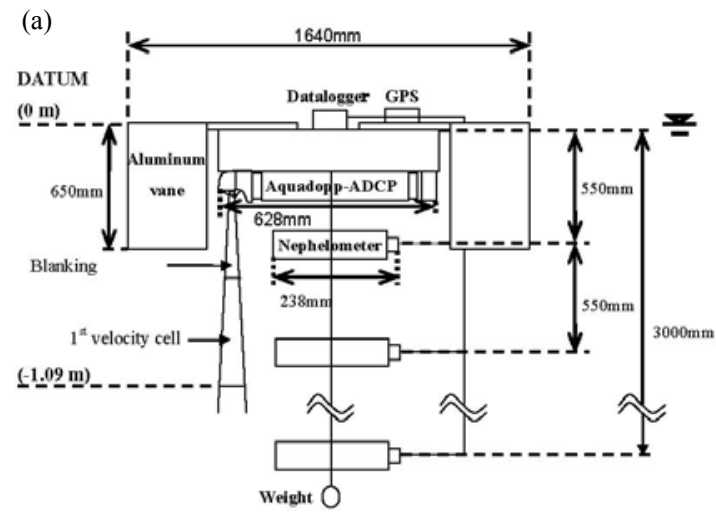

(b)

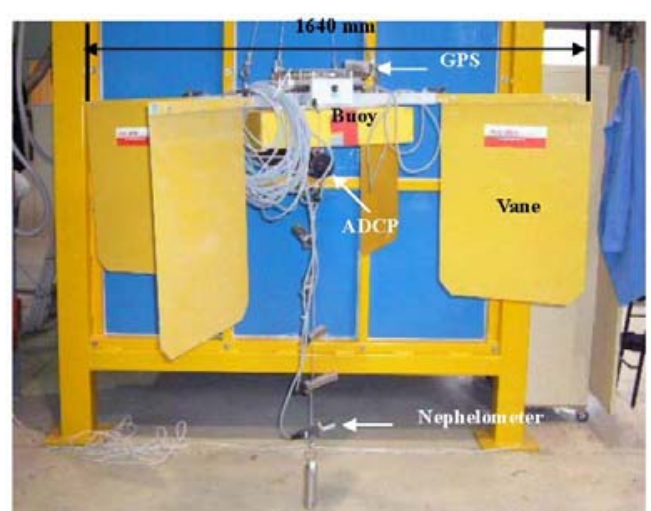

Figure 1. Illustration of the LAD-IT: Schematic diagram of the LAD-IT (a), and Photograph of LADIT (b). LAD-II equips GPS, ADCP and five nephelometers for Lagrangian measurement. This instrument also employs four vanes to catch water parcel. 


\section{LABORATORY AND FIELD EXPERIMENTS}

\section{Examinations of the LAD-IT accuracy measuring the current profiler}

Laboratory experiments conducted at an outdoor stream pool under uni-directional flow conditions

In order to analyse the performance of the LAD-IT under uni-directional flow velocity conditions, use was made of an outdoor stream pool in Kumamoto, Japan (Fig.2). The total length of the ellipseshaped pool is $160 \mathrm{~m}, 6 \mathrm{~m}$ width, and approximately $1 \mathrm{~m}$ depth. Three water jet pumps were used to generate uni-directional flow. To confirm velocity magnitude and vertical uniformity of flow velocity, an electromagnetic velocity meter, VE20, Kenek Instruments, was used to measure the vertical velocity profile at 12 positions with $20 \mathrm{~cm}$ intervals before conducting the experiments using the LAD-IT. In the experiments, four different conditions were tested to investigate the relationship between the profile interval of the ADCP and the current velocity (Table 1). The reference depth-average current velocity was found to be $0.29 \mathrm{~m} / \mathrm{s}$ when using three pumps and about $0.16 \mathrm{~m} / \mathrm{s}$ when one pump was operational. Under uni-directional flow conditions, the current profiler from the LAD-IT is estimated by summing the surface current velocity calculated from the GPS tracking and the relative current profiler using the ADCP.

(a)

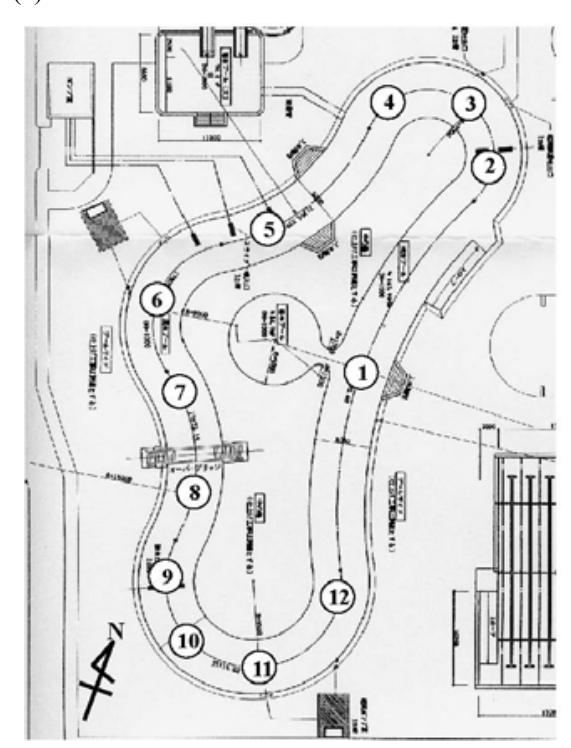

(b)

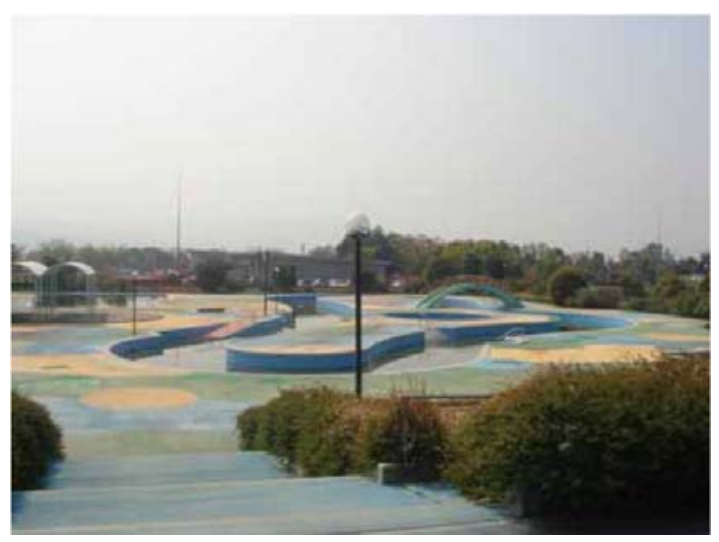

Figure 2. (a) Illustration of an outdoor stream pool in Kumamoto, Japan. Each number shows the points, where measured the vertical velocity profile. (b) Photograph of an outdoor stream pool.

Table 1. Laboratory experiment conditions conducted at the outdoor stream pool

\begin{tabular}{cccc}
\hline Run & $\begin{array}{c}\text { Profile interval of ADCP } \\
\text { (second) }\end{array}$ & $\begin{array}{c}\text { Number of working jet } \\
\begin{array}{c}\text { Reference depth-averaged } \\
\text { current velocity }(\mathrm{m} / \mathrm{s})\end{array}\end{array}$ \\
\hline $1^{\text {st }}$ & 20 & 3 & 0.29 \\
$2^{\text {nd }}$ & 60 & 3 & 0.29 \\
$3^{\text {rd }}$ & 60 & 1 & 0.16 \\
$4^{\text {th }}$ & 90 & 1 & 0.16 \\
\hline
\end{tabular}

*Reference depth-average current velocity was measured using the electromagnetic current meter.

Field experiments conducted in intertidal zone under multi-directional flow conditions

Filed experiments were conducted within intertidal zone adjacent to the Shirakawa River mouth in Ariake Sound, Kumamoto, Japan (Fig.3). The tide is semi-diurnal, and the mean spring tidal range is $3.86 \mathrm{~m}$. The average wave height and period are $0.2 \mathrm{~m}$ and $3 \mathrm{sec}$, respectively. Yamada and Kobayashi (2004) and Yamada et al. (2008) described the detailed characteristics of hydrodynamics and 
mophorodynamics in this zone, the suspended sediment transport plays an important role in the feeding mechanism for the macrobentos (Tamaki et al., 2008). The field experiments were conducted on 12 January 2008 from 10:00 am to 12:45 pm, which included a high tide (11:30 am). The water depth and the wind velocity magnitude and direction were measured every 10 minutes at Kumamoto Port. The weather conditions were windy and cloudy, with the maximum wind velocity magnitude being $7 \mathrm{~m} / \mathrm{s}$, while the minimum value was $2.9 \mathrm{~m} / \mathrm{s}$ during the study period, with the dominant wind being from the southwest. During this measurement period, the GPS recorded the path and co-ordinates of the LADIT every $1 \mathrm{sec}$ with an accuracy of within $\pm 15 \mathrm{~m}$. The Aquadopp-ADCP on the LAD-IT was set at 20cells/ensemble with a cell spacing of $0.2 \mathrm{~m}$ since the water depth was within $3 \mathrm{~m}$. It is noted that the blanking distance of the Aquadopp-ADCP is $20 \mathrm{~cm}$. The measuring interval of the Aquadopp-ADCP on the LAD-IT was $23 \mathrm{~Hz}$ and the profile interval was $60 \mathrm{sec}$, as the average velocity near the bed was about $0.2 \mathrm{~m} / \mathrm{s}$. To examine the measured velocity profile using the LAD-IT, the another type of the ADCP fitted with the bottom tracking, Workhorse, RD Instrument, referred to as Workhorse-ADCP, was deployed on a boat, which followed about $5 \mathrm{~m}$ behind the LAD-IT during the experiments. The number of cells of the Workhorse-ADCP was set at 100cells/ensemble and, the spacing of the cells was $0.05 \mathrm{~m}$, while the measuring interval was $1 \mathrm{sec}$ and the profile interval was $2 \mathrm{sec}$. Furthermore, a LISST-100, Sequoia Scientific, Inc, and AAQ1183 CTD, Alec Electronics, were employed for monitoring the vertical distributions of particle sizes, temperature, salinity and turbidity in every 30 minutes.

(a)

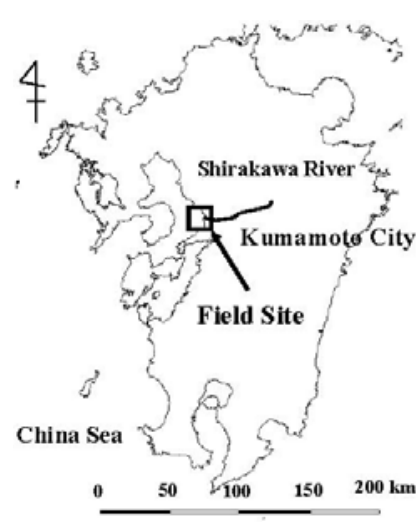

(b)

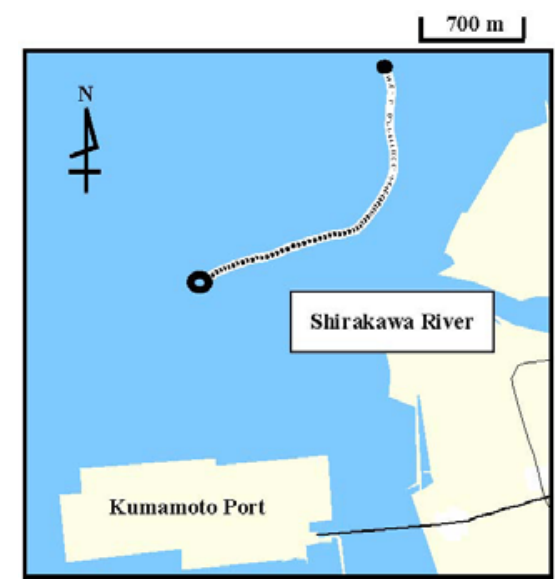

Figure 3. (a) Field site in Ariake Sound at the mouth of Shirakawa River in Kyushu Island, Japan. (b) Track of the LAD-IT measured by GPS at Shirakawa River mouth. Closed circle denotes the LAD-IT release location at 10:05 am and the open circle indicates the LAD-IT retrieval location at 12:45 pm.

Field experiments conducted on the Brisbane River to monitor the temporal and the spatial distribution of the current velocity and the suspended sediment concentration

A field experiment was conducted at the Brisbane River estuary, the hydrodynamics of which are forced by the tidal cycle in the vicinity of the river mouth. This estuary is macro-tidal sub-tropical and is located in the Moreton Bay region of southeast Queensland, Australia (Fig.4). The catchment area of the Brisbane River is approximately $13,560 \mathrm{~km}^{2}$ (Eyer et al., 1998) and the river depth varies $0.2-$ $1.9 \mathrm{~m}$ above mean sea level during spring tides and $0.5-1.4 \mathrm{~m}$ above mean sea level during neap tides. The input of marine sediment from Moreton Bay dominates the suspended sediments within this estuary during an average flow year. The field site was selected because of the usually observed high Suspended Sediment Concentrations (SSC), and has little or no boat traffic.

LAD-IT deployment was conducted from 11:00 am to 14:00 pm on 7 December 2006. The weather conditions were generally calm and sunny. During the experiments, there was a spring tide and the tide changed at 11:02 am at the Brisbane Bar. A water pressure gauge was deployed at the edge of the river during the investigation, and it was found the tide changed from flood to ebb at approximately $12: 30 \mathrm{pm}$ at the study site. Previous studies have revealed that the SSC suddenly 
decreases around the slack water (Mehta, 1986; Winterwerp, 2002). Therefore, the LAD-IT was released 1.5 hours before the tide changed $(11: 00 \mathrm{am})$ and retrieved 3 hours later $(14: 00 \mathrm{pm})$. The GPS measured the co-ordinates of the LAD-IT every $10 \mathrm{sec}$ within $\pm 15 \mathrm{~m}$ accuracy. The number of cells of the Aquadopp-ADCP was set at 30cells/ensemble and the spacing of the cells was $0.5 \mathrm{~m}$. Consequently, the total measuring distance was $15.4 \mathrm{~m}$, including a blanking distance of $0.4 \mathrm{~m}$. The measuring interval was $20 \mathrm{~Hz}$ and the profile interval was $60 \mathrm{sec}$. The five nephelometers were spaced over $3 \mathrm{~m}$ due to the water depth and the data recorded the turbidity every 5 minutes.

A NXIC CTD, Flamouth Scientific, was employed for the investigation to record the vertical distribution of conductivity, temperature and salinity. This sensor was lowered from the water surface to the bottom every 15 minutes, approximately $10 \mathrm{~m}$ distant from the LAD-IT, and operated at a frequency of $1 \mathrm{~Hz}$. Furthermore, bulk water samples were obtained at the same point as for the CTD measurement for the calibration from turbidity to SSC. The bulk water samples were collected approximately $0.55 \mathrm{~m}$ below the water surface at the depth of the first nephelometer measurement. These samples were vacuum filtered through pre-weighed glass-fiber papers and oven-dried to detect the total SSC. The Nephelometric Turbidity Unit (NTU) was then calibrated against the SSC.

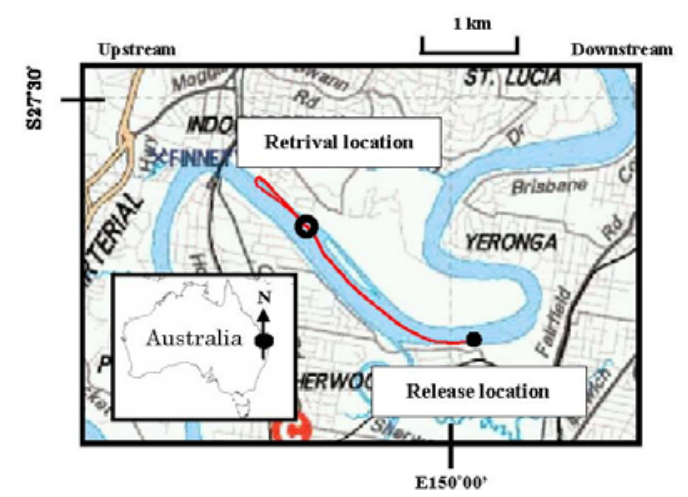

Figure 4. Track of the LAD-IT obtained by the GPS at the Brisbane River. The filled colored circle denotes the LAD-IT release location at 11:00 am and the void circle indicates the LAD-IT retrieval location at 14:00 pm.

\section{RESULTS}

\section{LAD-IT current profile accuracy}

Laboratory experiments conducted at an outdoor stream pool under uni-directional flow conditions

The surface current velocity was calculated from the measured LAD-IT (using the onboard GPS data), every $1 \mathrm{sec}$ within $\pm 15 \mathrm{~m}$ accuracy. The calculated surface current velocity was averaged during $60 \mathrm{sec}$ to remove fluctuations. An additional visual observation was carried out measuring the time gap between two points at a known distance for the comparison of the surface velocity. Fig.5 illustrates the time series of the surface velocity obtained by the GPS and the visual observation. This was good agreement between both measurements, the relative error being about $8 \%$. Furthermore, the spatial average current velocity near the water surface measured by the velocity meter was $0.27 \mathrm{~m} / \mathrm{s}$, and the surface velocity acquired by the GPS was $0.31 \mathrm{~m} / \mathrm{s}$. The relative error between these values was $12 \%$. Therefore, the GPS was judged to be adequate for measuring the surface current velocity under unidirectional flow.

The current profile was estimated by adding the relative velocity measured by the AquadoppADCP to the surface current velocity. As the water depth of the stream pool was $1 \mathrm{~m}$, the AquadoppADCP was able to measure the relative current velocity only for the first and second cells. The measuring depths of the two cells were $0.6 \mathrm{~m}$ and $0.8 \mathrm{~m}$ from the water surface. As the first step in estimating the current profile, the velocity magnitude was calculated as:

$$
V=\sqrt{u^{2}+v^{2}}
$$

where $u$ and $v$ are northward velocity $(+)$ and eastward velocity $(+)$, respectively and $V$ is the velocity magnitude. After this calculation, the direction of the velocity magnitude was transformed to the 
direction of the tracking of the LAD-IT obtained by the GPS, as the direction of the velocity magnitude corresponded to the direction of the surface velocity magnitude corresponded to the direction of the surface velocity but with an opposite sign. Finally, the current profile was estimated by adding the current velocity to the velocity magnitude at every measuring depth. Fig. 6 shows the time series of the current velocity measured by the LAD-IT. In this experiments, the average current velocity measured by the velocity meter was $0.3 \mathrm{~m} / \mathrm{s}$ at both depths. On the other hand, the average current velocity measured by the LAD was $0.32 \mathrm{~m} / \mathrm{s}$ at a depth of $0.6 \mathrm{~m}$ and the relative error was $7 \%$. Also, the average value was $0.3 \mathrm{~m} / \mathrm{s}$ at $0.8 \mathrm{~m}$, which was the same value as the velocity measured by the velocity meter. Therefore, the Aquadopp-ADCP, which is without bottom tracking, was found useful for measuring the relative current velocity at depths from the first cell of the Aquadopp-ADCP. Because the ability of measuring the velocity was verified under uni-directional flow, trial fieldwork investigations were performed.

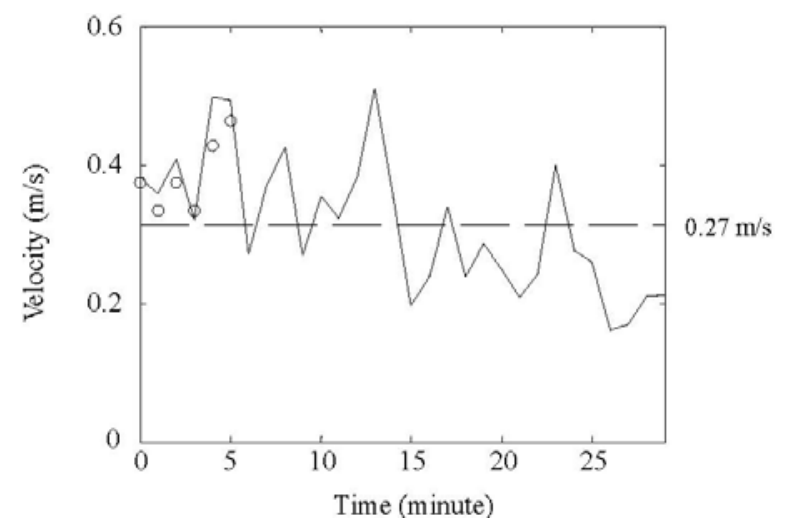

Figure 5. Time series of the measured surface velocity. The solid line indicates the surface velocity obtained from the GPS. The dashed line represented the average velocity measured from the GPS. The open circle shows surface velocity estimated from the visual observation.
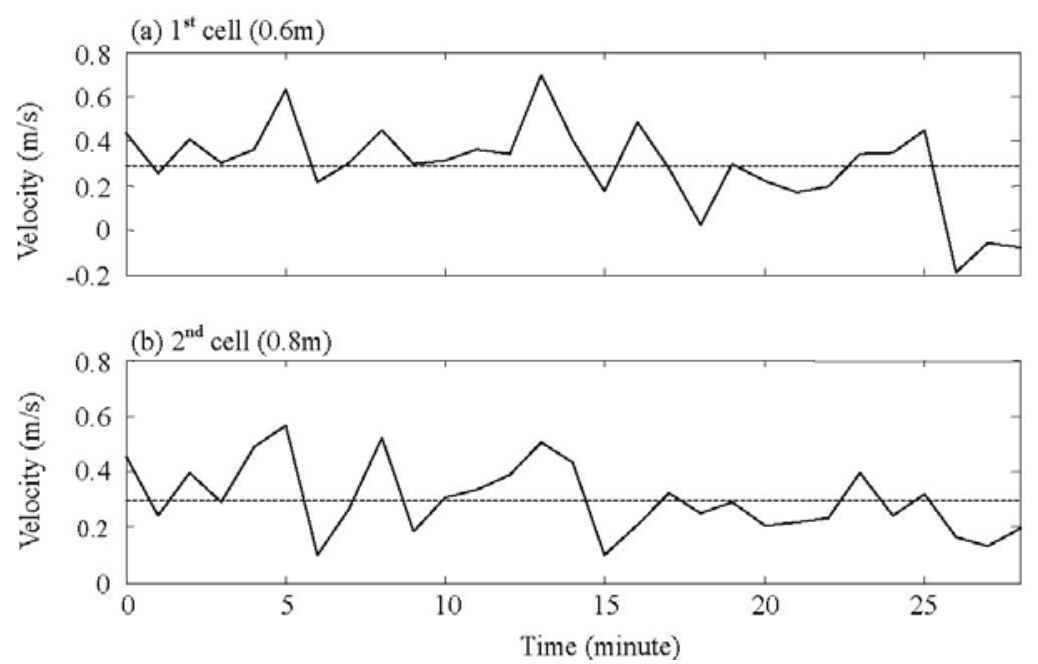

Figure 6. Time series of the current velocity measured by the LA-IT. The dashed line indicates the average velocity of each measurement height. The average value measured at $0.6 \mathrm{~m}$ was $0.32 \mathrm{~m} / \mathrm{s}$, and the average one measured at $0.8 \mathrm{~m}$ was $0.3 \mathrm{~m} / \mathrm{s}$.

Field experiments conducted within the intertidal zone under multi-directional flow conditions

During the field experiments within the intertidal zone adjacent to Shirakawa River mouth, the LAD-IT moved to the southeast until about 12:00 pm, then turned westward (Fig.3). A current-rip occurred near the river mouth during the experiments. The LAD-IT passed through the current-rip at around 12:00 pm. The average surface current velocity was $0.20 \mathrm{~m} / \mathrm{s}$ before crossing the current-rip, but this value increased to $0.40 \mathrm{~m} / \mathrm{s}$ in the current-rip due to the river discharge effects. Salinity, 
temperature and turbidity obtained by the AAQ also varied for the current-rip as shown in Fig.7. In this study, the AAQ sensor measured the practical salinity. The vertical salinity profile was stable before passing through the current-rip $(11: 30 \mathrm{am})$. The average value was 28.4 during this time. Within the current-rip, the salinity decreased above $1 \mathrm{~m}$ of depth. The minimum value was 5.6 in the upper water, and the average value was 28.5 below the depth of $1 \mathrm{~m}$. Additionally, salinity had a low value above the depth of $1.3 \mathrm{~m}$, and was stable below this water depth. During this time, the minimum value was 14.9 in the upper in the upper water. Turbidity had the opposite trend, decreasing with depth within the current-rip. The average value was 4.0FTU before crossing the current-rip, when turbidity increased above the depth of $1 \mathrm{~m}$. The maximum value in the upper water was $17.3 \mathrm{FTU}$ at 12:00 pm and 16.2FTU at 12:30 pm within the current-rip. However, the temperature remained constant, even within the current-rip. The average value was $13.0^{\circ} \mathrm{C}$ during the study period. It was cloudy during the measurement and rained one day before the investigation, therefore, freshwater from Shirakawa River affected the stratification.

(a) Salinity

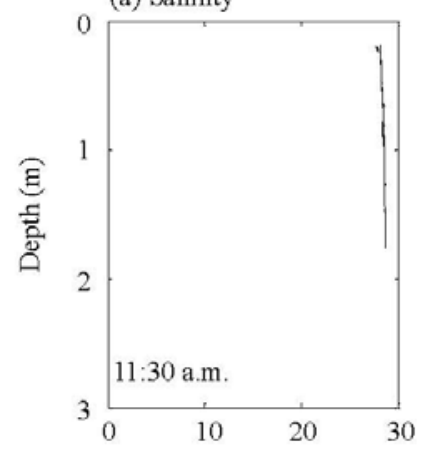

(b) Turbidity (FTU)

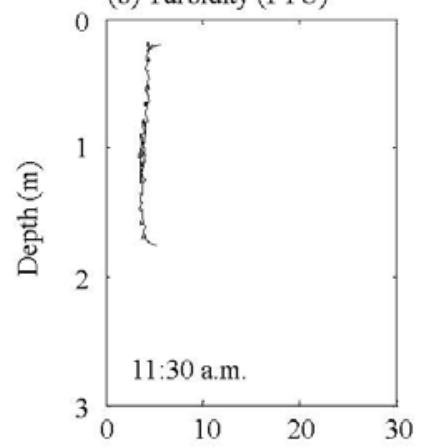

(c) Temperature (degree celsius)

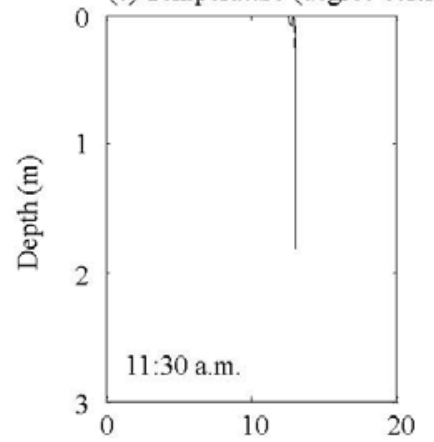

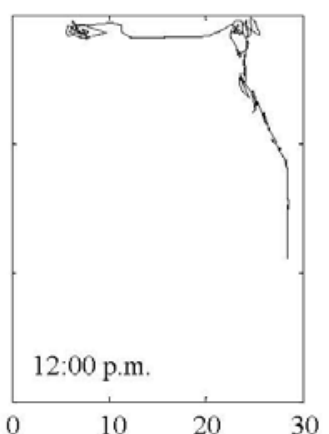
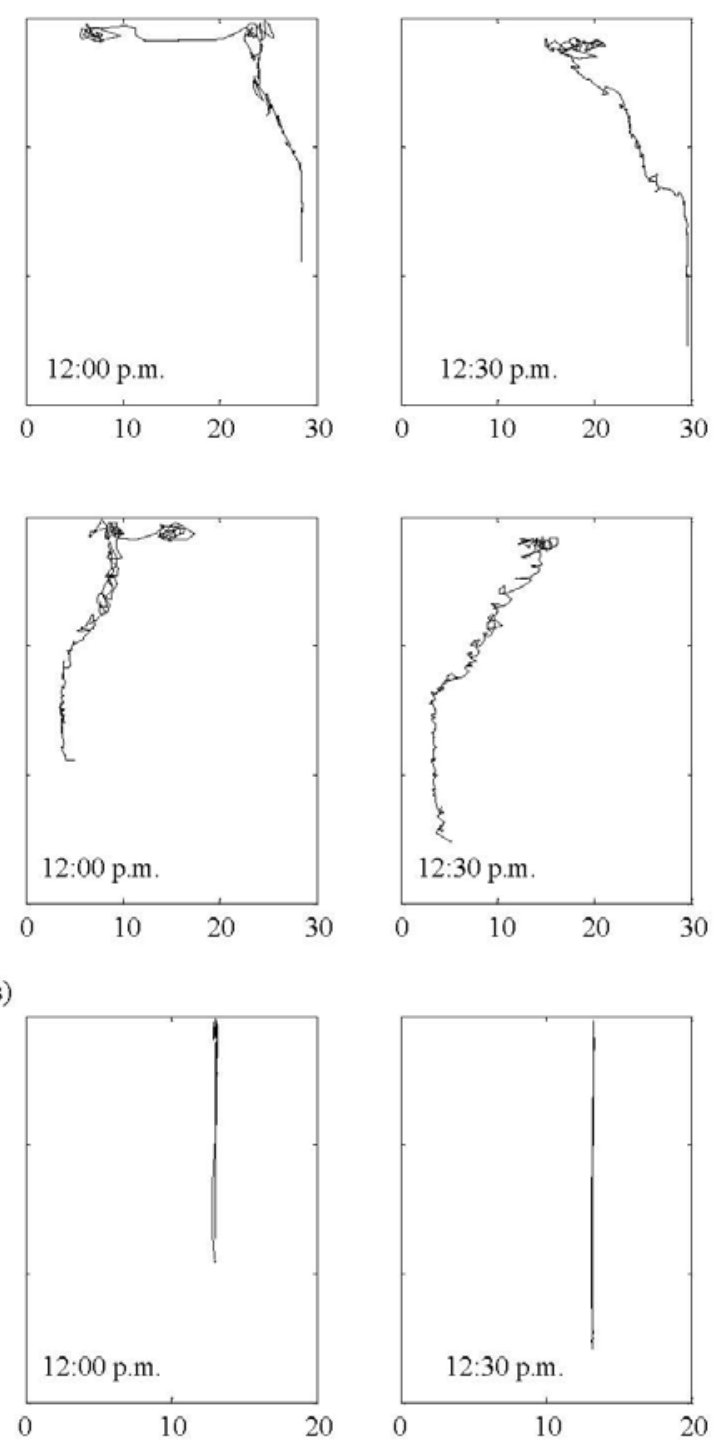

Figure 7. Vertical distribution of salinity (a), turbidity (b) and temperature (c) measured by the AAQ1183 sensor. Each value was acquired at 11:30 am, 12:00 pm and 12:30 pm, respectively. The LAD-IT went through the current-rip at approximately 12:00 pm. 
(a) 11:00 a.m.

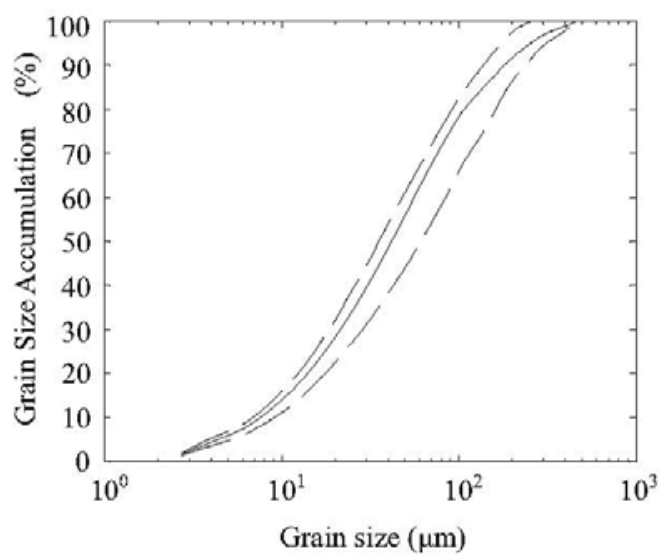

(b) 12:30 p.m.

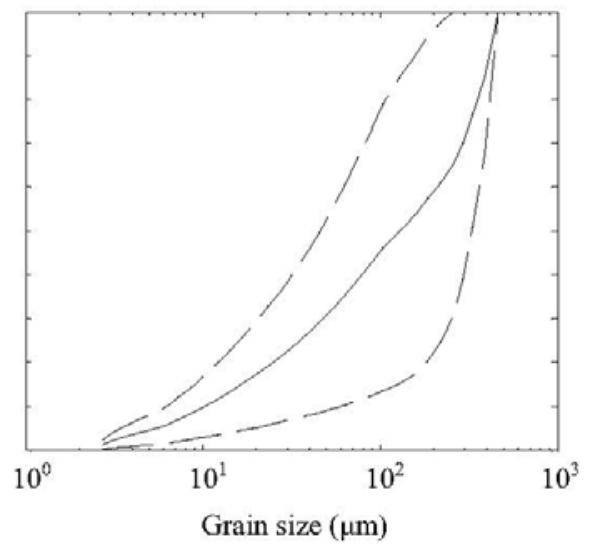

Figure 8. Grain size accumulation curve estimated using the data measured by the LISST-100. These data were obtained at 11:00 am (a), 12:30 pm (b). The solid line indicates calculated value and the dashed line shows the standard deviation.

The grain size accumulation curve was estimated using the particle sediment size measured using the LISST-100 (Fig.8). These data were taken at 11:00 am and 12:30 pm. The median grain size at these times was $50 \mu \mathrm{m}$ and $107 \mu \mathrm{m}$, respectively. The sediment size changed while passing through the current-rip. The median grain size was $44 \mu \mathrm{m}$ before 11:30 am with the average standard deviation along the water depth being 4.3\%. After 11:30 am, the median grain size was $107 \mu \mathrm{m}$ and the average standard deviation was $17 \%$, which was about four times greater than before 11:30 am. The LISST100 detected coarse grains at depths $<1 \mathrm{~m}$. This suggests that the river flow contributes to support larger particles in the upper water. The standard grain size was estimated as $252 \mu \mathrm{m}$ from the bed sampling as this site. Consequently, the fundamental mud flat consisted of sediment approximately six times coarser than the suspended sediment. The freshwater inflow from Shirakawa River also affected the vertical velocity profile.

Data collected with the Workhorse-ADCP during this investigation showed the principal velocity direction was southward at $0.13 \mathrm{~m} / \mathrm{s}$ before crossing the current-rip, with the vertical velocity distribution also varying within the current-rip, where increased to $0.28 \mathrm{~m} / \mathrm{s}$ with westward direction. However, there was no remarkable torsion of the velocity profile during the investigation. Therefore, these vertical velocity distributions were compared with the data measured by the LAD-IT.

For a comparison of the current profiler, the velocity magnitude was estimated by Eq. (1). In this study, the current profile from the LAD-IT was calculated using two methods. One method added the relative current velocity observed by the Auadopp-ADCP to the surface current velocity obtained by GPS track, while the other used only the Aquadopp-ADCP data (Fig.9). The reference current profile was measured using the Workhorse-ADCP on the boat. These values were averaged over 60 sec, because the LAD-IT estimated without using the surface current velocity was in good agreement with the value given by the Workhorse-ADCP. However, the velocity magnitude of the LAD-IT calculated including the surface current velocity was approximately twice that given by the Workhorse-ADCP. Additionally, the current profiles measured by the LAD-IT increased towards the bottom. The velocity magnitude differences calculated without and with the surface velocity were $0.10 \mathrm{~m} / \mathrm{s}$ and $0.27 \mathrm{~m} / \mathrm{s}$, respectively. Each value was twice that before crossing the current-rip. Furthermore, the velocity magnitude estimated with the surface velocity was greater than that obtained by the Workhorse-ADCP, and the difference was about twice the value calculated without the surface current velocity during the experiments. This indicates the method of measuring the current profile using the LAD-IT under multi-directional flow is different from the method under uni-directional flow.

The multi-directional flow under oscillatory waves has a different system of mass transport to that of the uni-directional flow. Based on the linear wave theory, the Eulerian mass transport velocity is given by:

$$
\bar{U}=\frac{1}{8} k \sigma H^{2} \cdot \frac{\cosh 2 k\left(h+z_{0}\right)}{\sinh ^{2} k h}
$$


where $\bar{U}$ is the mass transport velocity, $k$ is the wave number, $\sigma$ is the angular frequency, $H$ is the wave height, $h$ is the water depth and $z_{0}$ is the distance to the bottom. In this case, the wavelength was $11.3 \mathrm{~m}$, the wave period was $3 \mathrm{sec}$, the wave height was $0.2 \mathrm{~m}$ and the water depth was $2 \mathrm{~m}$ (Yamada and Kobayashi, 2004). Consequently, the mass transport velocity was $0.01 \mathrm{~m} / \mathrm{s}$. This implies that LAD-IT moved with this slow velocity. Therefore, the measurement of the internal current velocity using the LAD-IT may be equal to that of an investigation at fixed point. When the velocity magnitude measured by the Workhorse-ADCP is compared with the acquired data from the LAD-IT, the velocity magnitude calculated using the surface current velocity had a larger difference than that calculated without using the surface velocity (Fig.9). This also indicates it was possible to measure the current profile using only the Aquadopp-ADCP, without having the bottom tracking ability, equipped on the LAD-IT under multi-directional flow.

For the verification of the ability to measure the current profile, the data observed by the LAD-IT was divided into data obtained before and after crossing the current-rip. The average surface current velocity was $0.36 \mathrm{~m} / \mathrm{s}$ within the current-rip. Although the wind velocity was less than that before passing the current-rip, the surface velocity increased within the current-rip. This implies the water parcel near the water surface was affected by the river flow. Therefore the LAD-IT captured the surface current velocity in the current-rip. Consequently, the data before crossing the current-rip were employed for a comparison with the velocity observed by the Workhorse-ADCP. Additionally, when the Workhorse-ADCP recorded noise because of interference with other instruments such as the LISST-100 and AAQ1183, these data were rejected from the ensemble data. After separating the data, the depth-mean velocity was estimated by:

$$
\ddot{U}=\frac{1}{(h+\eta)} \int_{-h}^{\eta} u(z) d z, \ddot{V}=\frac{1}{(h+\eta)} \int_{-h}^{\eta} v(z) d z
$$

where $h$ is the water depth below the still waster level, $\eta$ is the free surface above the still water line, and $\ddot{U}, \ddot{V}$ are the depth-mean velocity northward (+), eastward velocity. The uniform velocity obtained using the Workhorse-ADCP, and the relative error was found to be within $3.5 \%$, which suggests the LAD-IT was able to measure the current profile in the Lagrangian framework under multi-directional flow. Furthermore, the Aqudopp-ADCP directly measured the current profile under multi-directional flow.
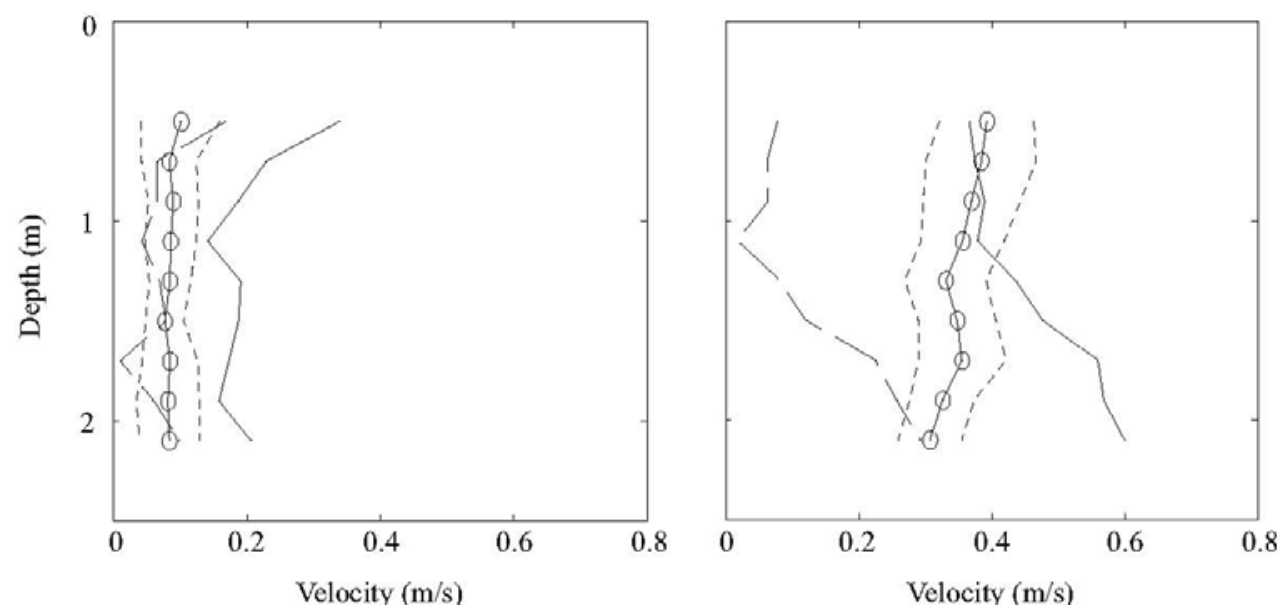

Figure 9. Current profile measured by the LAD-IT and the Workhorse-ADCP, which deployed on the boat. The left panel shows the velocity observed before passing through the current-rip. The right panel shows the velocity measured within the current-rip. The solid line with circle and the doted line show the measured value by Workhorse-ADCP and its standard deviation, respectively. The solid line indicates the measured current profile using the LAD-IT summing the surface velocity obtained from the GPS and the relative current profile obtained the Auadopp-ADCP deployed on the LAD-IT. The dashed line represents the velocity measured using the Aquadopp-ADCP only deployed on the LAD-IT. 


\section{Measured temporal and spatial distributions of the current velocity and the suspended sediment concentration on the Brisbane River}

The tracking of the LAD-IT is shown in Fig.4. The LAD-IT went upstream with the flood tide, changed the direction at approximately 13:00 pm and went downstream with the ebb tide (total traveling distance of $3.9 \mathrm{~km}$ ). A water pressure gauge detected that the tide changed at approximately $12: 30 \mathrm{pm}$. In this section, the slack water defined as the time that the velocity acquired by the GPS was a minimum. This is the time when the net flow forces acting on the surface areas of the drogue vanished and the drogue progressively changed direction. Using this definition, the slack occurred at 12:57 pm. Generally, a time lag exists between the high tide and the slack water due to the bed friction, the tidal inertial forces and the asymmetries in estuaries. To examine these phenomena, the current profile was estimated using the LAD-IT.

The current profile was estimated a depth of $5.4 \mathrm{~m}$, which corresponded with the depth of the $10^{\text {th }}$ measuring cell of the Aquadopp-ADCP, although turbidity was measured to the depth of $3 \mathrm{~m}$. Timespace distributions of turbidity and the internal horizontal and vertical velocities are shown in Fig.10 (a)-(c). These figures were obtained by interpolating the measured data using the cubic spline method. The CTD measurement showed little stratification within the water column during the experiments. Turbidity distribution seemed to maintain a uniform profile until 12:30 pm, but the vertical averaged suspended sediment concentration suddenly dropped between 12:30 pm and 13:30 pm, then increased again gradually after 13:30 pm. The current profile was estimated by Eq. (1), and the direction corresponded with the surface velocity. The surface velocity decreased until the slack water before increased to $0.4 \mathrm{~m} / \mathrm{s}$ at $14: 00 \mathrm{pm}$. Expectedly, the horizontal velocity decreased until the slack water before increased again, but in the opposite direction. These results corresponded to the time-space distribution of turbidity measurements. However, the vertical velocity did not change much during the slack water.
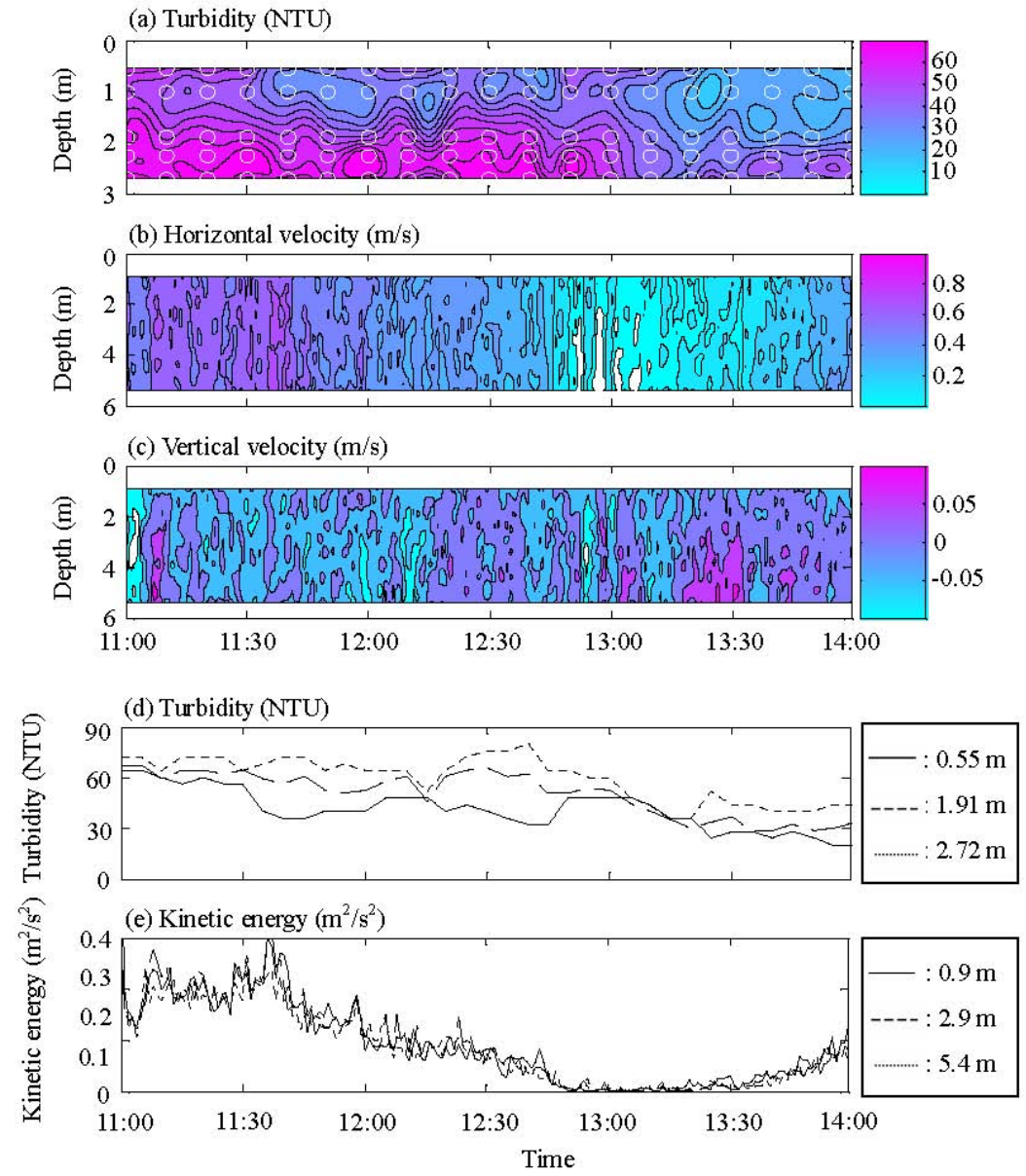

Figure 10. Time-space distribution of interpolated by the spline method and time series of turbidity and the kinetic energy estimated using the horizontal and vertical velocity. (a) Turbidity. (b) Horizontal velocity with the same direction of the surface velocity obtained by the GPS. (c) Vertical velocity. An empty white cycle indicates the depth of deployment of nephelometers every 10 minutes in figure (a). Also, the positive value indicates up-direction and negative value means down-direction in figure (c). (d) Time series of turbidity measured at $0.55 \mathrm{~m}, 1.91 \mathrm{~m}$ and $2.72 \mathrm{~m}$. (e) Time series of the kinetic energy obtained at $0.9 \mathrm{~m}, 2.9 \mathrm{~m}$, and $5.4 \mathrm{~m}$. 


\section{DISCUSSION}

Lagrangian field experiments using the LAD-IT were carried out at the Brisbane River estuary to measure the temporal and spatial distributions of the suspended sediment dynamics. This estuary always maintains high SSC and is dominated by tidal cycle. Temporal and spatial distribution of turbidity decreased at the high tide and suddenly sank during the slack water (Fig.10 (a)-(c)), which may suggest the horizontal velocity plays an important role in the sediment transport dynamics (eg., Winterwerp et al., 2006). A high velocity yields a certain shear stress and sediment then resuspends from the bed into the water column (Metha, 1986).

Winterwerp et al. (2006) suggested that the turbulent kinetic energy is an important parameter in a three-dimensional sediment transport model. To examine the relationship between turbidity and the internal horizontal and vertical velocities assuming the turbulent energy is proportional to the kinetic energy to the average flow fields. This assumption was used due to the lack of the high-resolution velocity data in this experiment. The time series of turbidity and the kinetic energy are shown in Fig.10 (d) and (e). The kinetic energy was calculated using the horizontal and vertical velocities as:

$$
E=\frac{1}{2}\left(u^{2}+v^{2}+w^{2}\right)
$$

where $w$ is the vertical velocity (upward : + ) and $E$ is the kinetic energy. The horizontal velocity dominated in the kinetic energy fields because the vertical velocity was one order of magnitude smaller than the horizontal velocity (Fig.10 (b), (c)). Turbidity decreased towards the water surface, but the kinetic energy remained fairly uniform with depth. When the kinetic energy remained above $0.05 \mathrm{~m}^{2} / \mathrm{s}^{2}$ before the high tide $(12: 30 \mathrm{pm})$, turbidity was stable at each depth. When the kinetic energy dropped below $0.05 \mathrm{~m}^{2} / \mathrm{s}^{2}$, turbidity suddenly decreased $(12: 57 \mathrm{pm})$. After the slack water, the kinetic energy was less than $0.05 \mathrm{~m}^{2} / \mathrm{s}^{2}$, but turbidity increased again at depth. Furthermore, turbidity increased at 11:30 am and then decreased between 12:00 pm and 12:30 pm, the kinetic energy followed a similar trend over the same time.

In order to interpret the above phenomena physically, the following equation was taken into account before the slack water (11:00 am-12:00 pm).

$$
w_{s} \cdot \bar{C}=-\varepsilon_{z} \cdot \frac{\partial \bar{C}}{\partial z}
$$

where $\bar{C}$ is the average sediment concentration for one wave period, $w_{s}$ is the settling velocity and $\varepsilon_{z}$ is the turbulent diffusion coefficient within the z-coordinate. The left-hand side of this equation represents the settling flux, while the right-hand side represents the resuspension flux. Because turbidity was stable before the high tide, the settling flux balanced with the resuspension flux. The turbulent kinetic energy supported the upward resuspension flux, and the kinetic energy contributed to the resuspended the sediment dynamics, consequently. During the slack water, however, the following equation seems to become established based on the flux balance:

$$
w_{s} \cdot \bar{C}>-\varepsilon_{z} \cdot \frac{\partial \bar{C}}{\partial z}
$$

When the kinetic energy became low, the downward settling flux was greater than the upward resuspending flux. Consequently, the suspended sediment started to settle downward during the slack water. After the slack water, turbidity increased gradually and the resuspending flux increased with the kinetic energy. This result indicates the possibility that the kinetic energy is another key parameter for predicting the suspended sediment dynamics.

\section{CONCLUSIONS}

An improved in-situ Lagrangian drogue for monitoring the temporal and spatial distributions of both the current velocity and the suspended sediment concentration within the intertidal environments has been developed based on the Lagrangian-Acoustic Drogue (LAD) presented by Schacht and Lemckert (2007). The new drogue is called the LAD for Inter-Tidal environments (LAD-IT) and it was equipped with a small ADCP (without a bottom tracking ability) because the LAD-IT was designed for using in very shallow water regions where the lager ADCPs were not suitable. The accuracy of measuring the current profile by the LAD-IT was examined in both uni-directional and 
multi-directional flow conditions. Under uni-directional conditions, such as that of a river, the current profile is expressed within $15 \%$ accuracy as a sum of the surface velocity calculated by GPS tracking and the relative current profile measured by the ADCP. However, under multi-directional conditions, such as that of wind waves, the current profile agree directly with the profile measured using the ADCP within 5\% accuracy.

The temporal and spatial distributions of both the current velocity and the suspended sediment concentration were measured using the LAD-IT on Brisbane River, Australia, under uni-directional flow conditions. The field observation results support the conventional concept observed under laboratory conditions that the suspended sediment is the result of a vertical balance between the downward suspended sediment settling and the upward turbulent diffusion fluxes (e.g. Winterwerp et al., 2006). However, the field measurements within multi-directional flow environments are necessary to confirm the adaptability for the temporal and spatial distributions of both the current velocity and the suspended sediment concentration within wind-induced wave environments. Furthermore, a future study is desirable, that combining both Lagrangian and Eulerian approaches for estimating sediment transport parameters, such as settling velocity and resuspnesion rate within the estuaries and the intertidal environments.

\section{ACKNOWLEDGMENTS}

This study was supported by a grant from the Bilateral Joint Research Project between Japan and Australia and by a Grant-in Aid for Scientific Research from the Japan Society for the Promotion of Science. The authors would like to thank the laboratory staff of Griffith University (Geoffrey Turner, Malcolm Duncan and Warren Broe) and Dr. Yamamoto of Yamaguchi University and Dr. Hamada of Saga University for their assiatance in the filed experiments. Mr. Hokamura participated in the field experiments and made the significant contributions to this study.

\section{REFERENCES}

Dyer, K.R., Comelisse, J., Dearnaley. M.P., Fennessy, M.J., Jones, S.E., Kappenberg, J., McCave, I.N., Pejrup, M., Puls, W., Leussen, W.V. and Wolfstein, K. 1996. A comparision of in situ techniques for estuarine floc settling velocity measurements, J of Sea Research, 36, 15-29.

Eyer, B., Hossain, S. and McKee, L. 1998. A suspended sediment budget for the modified subtropical Brisbane River estuary, Estuarine, Coastal and Shelf Science, 47, 513-522.

Fugate, D.C. and Friendrichs, C.T. 2002. Determining concentration and fall velocity of estuarine particle populations using ADV, OBS and LISST, Continental Shelf Research, 22, 1867-1886.

Gartner, J.W., Cheng, R.T., Wang, P.F. and Richter, K. 2001. Laboratory and field of the LISST-100 instrument for suspended particle size determinations, Marine Geology, 175, 199-219

Geyer, W.R., Hill, P.S. and Kineke, G.C. 2004. The transport, transformation and dispersal of sediment by coastal flows, Continental Shelf Research, 24, 927-946.

Guichard, F., Levin, S.A., Hastings, A. and Siegel, D. 2004. Toward a dynamic metacommunity approach to marine reserve theory, Bioscience, 54, 1003-1011.

Hill, D.C., Jones, S.E. and Prandle, D. 2003. Derication of sediment resuspension rates from acoustic backscatter time-series in tidal waters, Continental Shelf Research, 23, 19-40.

Holdaway., G.P., Thorne, P.D., Flatt, D., Jones, S.E. and Prandle, D. 1999. Comparison between ADCP and transmissiometer measurements of suspended sediment concentration, Continental Shelf Research, 19, 421-441.

Hossain, S., Eyer, B.D. and McKee, L.J. 2004. Impacts of dredging on dry season suspended sediment concentration in the Brisbane River estuary, Queensland, Australia. Estuarine, Coastal and Shelf Science, 61, 539-545.

Johnson, D. and Pattiaratchi, C. 2004. Application modeling and validation of surfzone drifters, J. of Coastal Engineering, 51, 455-471.

Mehta, A.J. 1986. Characterization of cohesive sediment properties and transport processes in estuaries, Lecture Notes on Coastal and Estuarine, 14, 290-325.

Mikkelsen, O.A. and Pejrup, M. 2000. In situ particle size spectra and density particle aggregates in a dredging plume, Marine Geology, 170, 443-459.

Mikkelsen, O.A., Hill, P.S. and Milligan, T.G. 2006. Single-grain, microfloc volume variations observed with a LISST-100 and a digital floc camera, J. of Sea Research, 55, 87-102. 
Naudin, J.J., Gauwet, G., Chretiennot-Dinet, M.J., Deniaux, B., Devenon, J.L. and Pauc, H. 1997. River discharge and wind influence upon particulate transfer at the land-ocean interaction, case study of the Rhone River plume, Estuarine, Coastal and Shelf Science, 45, 303-316.

Niller, P.P., Sybrandy, A.S., Bi, K., Poilain, P.M. and Bitterman, D. 1995. Measurement of the water following capability of holey-sock and TRISTAR drifters, Deep-Sea Research, I, 42, 1951-1964.

Nishi, T., Lemckert, C. and Yamada, F. 2007. Eulerian-Lagrangian measurements for estimating the sediment transport parameters in estuary, Annual L. of Coastal Engineering in Japan, 54, 14211425 (In Japanese with English abstract).

Righi, D.D. and Strub, P.T. 2001. The use of simulated drifters to estimate velocity, J. of Marine Systems, 29, 125-140.

Schacht, C. and Lemckert, C. 2007. A new Lagrangian-Acoustic Drogue (LAD) for monitoring flow dynamics in an estuary a quantification of its water-trackin ability, J. of Coastal Research, SI50, 420-426.

Schmidt, W.E., Woodward, B.T., Millikan, K.S., Guza, R.T., Raubenheimer, B., Elger, S. 2003.A GPS-tracked surf zone drifter, J. of Atmospheric and Ocean Technology, 20, 1069-1075.

Schmidt, W.E., Guza, R.T. and Slinn, D.N. 2005. Surf zone currents over irregular bathymetry: Drifter observations and numerical simulations, J. of Geophysical Research, 110, 1-19.

Siegel, D.A., Kinlan, B.P., Gaylord, B. and Gaines, S.D. 2003. Lagrangian descriptions of marine larval dispersion, Marine Ecology Progress Series, 260, 83-96.

Sternberg, R.W., Berhane, I. and Ogston, A.S. 1999. Measurement of size and settling velocity of suspended aggregates on the northern California continental shelf, Marine Geology, 154, 43-53.

Tamaki, A., Nakaoka, A., Maekawa, H. and Yamada. F. 2008. Spatial partitioning between species of the phytoplankton-feeding guild on an estuarine intertidal sandflat and its implication on habitant carrying capacity, Estuarine, Coastal and Shelf Science, 78, 727-738.

Van Leussen, W. 1999. The variability of settling velocities of suspended fine-grained sediment in the Ems estuary, J. of Sea Research, 36, 77-81.

Voulgaris, G. and Meyers, S.T. 2004. Temporal variability of hydrodynamics, sediment concentration and sediment settling velocity in a tidal creek, Continental Shelf Research, 24, 1659-4683.

Winterwerp, J.C. 2002. On the flocculation and settling velocity of estuarine mud, Continental Shelf Research, 22, 1339-1360.

Winterwerp, J.C., Manning, A.J., Martens, C., de Mulder, T. and Vanlede, J. 2006. A heuristic formula turbulence-induced flocculation of cohesive sediment, Estuarine, Coastal and Shelf Science, 68, 195-207.

Yamada, F. and Kobayashi, N. 2004. Annual variations of tide level and mudflat profile, J. of Waterway, Port, Coastal and Ocean Engineering, 130, 119-126.

Yamada, F., Kobayashi, N., Sakanishi, Y. and Tamaki, A. 2009. Phase averaged suspended sediment fluxes on intertidal mudflat adjacent to river mouth, $J$. of Coastal Research, 25, 350-358. 